\title{
Reply to the Letter by Kaya et al. Entitled 'Temperature Control Function of the Choroid May Be the Reason for the Increase in Choroidal Thickness During the Acute Phase of Familial Mediterranean Fever'
}

\author{
Fatih C. Gundogan ${ }^{\mathrm{a}}$ Salih Uzun ${ }^{\mathrm{b}}$ Gökhan Özge ${ }^{\mathrm{a}}$ Fahrettin Akay $^{\mathrm{c}}$ \\ ${ }^{a}$ Department of Ophthalmology, Gulhane Military Medical Academy, and ${ }^{\mathrm{b}}$ Department of Ophthalmology, \\ Etimesgut Military Hospital, Ankara, and ${ }^{\mathrm{C}}$ Department of Ophthalmology, Izmir Military Hospital, Izmir, Turkey
}

\section{Dear Editor}

We read Kaya et al.'s comments [1] on our article entitled 'Choroidal Thickness Changes in the Acute Attack Period in Patients with Familial Mediterranean Fever' [2] with great interest. Kaya et al. [1] assert that there is no evidence of inflammation in the choroid during the acute phase of familial Mediterranean fever (FMF). The authors claim that if an inflammation was present, a uveitic presentation like VogtKoyanagi-Harada disease would be seen in the patients. We think it is probable that the systemic inflammatory and vasculopathic nature of FMF causes increased vascular permeability, exudation and enlargement of the choroidal vessels during the acute attacks, which give rise to an increase in choroidal thickness. The strongest sup-

\section{References}

1 Kaya A, Aksoy Y, Sevinc MK, Diner O: Temperature control function of the choroid may be the reason for the increase in choroidal thickness during the acute phase of familial Mediterranean fever. Ophthalmologica 2016 DOI: $10.1159 / 000443849$.

-2 Gundogan FC, Akay F, Uzun S, Ozge G, Toyran S, Genç H: Choroidal thickness changes in the acute attack period in patients with $\mathrm{fa}$ milial Mediterranean fever. Ophthalmologica 2015, DOI: $10.1159 / 000442216$.

-3 Aytekin S, Aydin F, Akpolat T, Senturk N, Turanli AY: Evaluation of nailfold capillaries porters of this assumption are the positive correlations between the choroidal thickness and the indicators of inflammation such as erythrocyte sedimentation rate, fibrinogen and C-reactive protein levels. These findings suggest that an increase in the severity of the inflammatory reaction causes an increase in the choroidal thickness in patients with FMF. Additionally, some clinical studies also demonstrated vascular capillary enlargement, tortuosity and extravasation in nail folds of patients with FMF [3, 4]. Another important point is that not all inflammatory conditions of choroid have funduscopic findings, even Vogt-Koyanagi-Harada disease [5, 6]. Kaya et al. [1] hypothesized that the cause of increase in choroidal thickness may be the temperature control function of the choroid. As mentioned in the methods section of our study [2], body temperature of all patients was within normal limits. The patients were on colchicine treatment and received nonsteroidal anti-inflammatory drugs when they had fever and/or pain. Parver et al. [7] suggested that increased choroidal circulation is necessary for the maintenance of a stable temperature in the outer layers of the retina in monkeys. On the other hand, changes in choroidal blood flow were reported not only in the lightstimulated eye but also in the contralateral eye in human studies [8], indicating that the response of choroidal blood flow is under neural control rather than local temperature. in familial Mediterranean fever patients. Clin Rheumatol 2011;30:255-257.

4 Dinc A, Melikoglu M, Korkmaz C, Fresko I, Ozdogan H, Yazici H: Nailfold capillary abnormalities in patients with familial Mediterranean fever. Clin Exp Rheumatol 2001;19:S42-S44.

5 Sakata VM, da Silva FT, Hirata CE, Takahashi WY, Costa RA, Yamamoto JH: Choroidal bulging in patients with Vogt-Koyanagi-Harada disease in the non-acute uveitic stage. J Ophthalmic Inflamm Infect 2014;4:6.

-6 Tagawa Y, Namba K, Mizuuchi K, Takemoto Y, Iwata D, Uno T, Fukuhara T, Hirooka K,
Kitaichi N, Ohno S, Ishida S: Choroidal thickening prior to anterior recurrence in patients with Vogt-Koyanagi-Harada disease. Br J Ophthalmol 2015, DOI: 10.1136/bjophthalmol-2014-306439.

7 Parver LM, Auker C, Carpenter DO: Choroidal blood flow as a heat dissipating mechanism in the macula. Am J Ophthalmol 1980; 89:641-646.

8 Fuchsjager-Mayrl G, Polska E, Malec M Schmetterer L: Unilateral light-dark transitions affect choroidal blood flow in both eyes. Vision Res 2001;41:2919-2924.

\section{KARGER}

E-Mail karger@karger.com

www.karger.com/oph
C 2016 S. Karger AG, Base

0030-3755/16/2352-0124\$39.50/0
Fatih C Gundogan, MD

GATA

Göz Hst AD

TR-06200 Ankara (Turkey)

E-Mail fgundogan@yahoo.com 